\title{
Are male to female employment ratio and salary compensations in agricultural sector co- integrated?
}

\author{
Evgenia Ezhak $^{1}$, Tatiana Podolskaya $^{2}$, Elizaveta Karagozova $^{2}$, Muhammad Imtiaz \\ Subhani ${ }^{3}$, and Denis Ushakov ${ }^{4, *}$ \\ ${ }^{1}$ Rostov State Transport University, Rostov-on-Don, Russia \\ ${ }^{2}$ Russian Presidential Academy of National Economy and Public Administration, South institute of \\ Management, Rostov-on-Don, Russia \\ ${ }^{3}$ ILMA University, Karachi, Pakistan \\ ${ }^{4}$ Suan Sunandha Rajabhat University, Bangkok, Thailand
}

\begin{abstract}
This study has been conducted in order to identify whether there is the co-movements between Male to Female employment ratio and Salary compensations in agricultural sector of Pakistan. To analyze the possible co-movement between the Male to Female employment ratio and Salary compensations in agricultural sector of Pakistan, the time series data for the yearly period of 1990 to 2020 for agriculture sector are taken from the publically available source i.e. website of World Bank. The result indicated that there is a long term relationship exists in between Male to Female employment ratio and Salary compensations in agricultural sector of Pakistan.
\end{abstract}

\section{Introduction}

Gender favoritism brings up to beliefs and positions in reference to the gender of a person, such opinions and positions are of a cultural nature and don't, generally, behave some legitimate issues. Gender favoritism, then again, may bear lawful outcomes. Although what comprises gender favoritism changes between states, the effect constitutes that it is an unfavorable action adopted by one individual versus different individual that wouldn't make happened had the individual constituted of some other gender.

Favoritism of that nature doubtful counted a circumstance is banned in many nations. Presently, favoritism supported gender is characterized as harmful legal action versus different individual, which wouldn't have took place experienced the individual represented of another gender. This is believed a constitute of bias and comprises no legal in certain counted conditions in almost nations. Gender favoritism could boost up in incompatible conditions.

For example an employee possibly discriminated versus by being called for unfavorable inquiries during a employment interview, or because an employer didn't take, rise or unlawfully terminated an employee supported his or her sex, or employers wage unevenly

\footnotetext{
*Corresponding author: denis.us@ssru.ac.th
} 
settled on sex. In an informative adjusting at that place may be claims that an educate was expelled by an informative establishment, program, chance, loan, scholar group, or encyclopaedism referable his or her sex.

In the housings background at that place could represent claims that an individual was rejected dialogues on searching a house, signing/leasing a home or acquiring a loan supported his or her sex. Some other background where at that place have made up claims of sex favoritism is depositing; for instance whenever one is denied deferred payment or is proposed unbalanced loan conditions supported peerless gender. So, in this research focus is on the impact of Gender Difference on Compensation.

Due to change in society, the behavior of the people living in this society has rapidly changed. People are now moving at a very fast pace. Both the genders are striving hard to reach ahead of each other. This study primarily focuses on male to female ratio and its comovement with salary compensations in agriculture sector of Pakistan.

\section{Literature Review}

[1] examined penetrations into the go through by women hopeful to the CEO attitude, especially viewing qualifications and compensation anticipations. The ExecuComp database of administrators at 1500 biggest America corporations by 1992 to 2004 represented accustomed discover women chief executive officer's and to analyze sex differences of opinion in recompense of executives accomplished that period. [1,2] investigated deviations in recompense related sex concentrations between industries at a different organization points of direction to distinguish gender-based designs of recompense at the large point not looked into in early analyzes that merely advise diligence or occupational conflicts.

It based on information of the existent Population eyeshots and the Standard \&Poor's Index ExecuComp database examined conflicts in recompense of managers and business leader. The findings show that adult male and adult female must try to find a different paths and resultants to optimize compensation.

In that respect are sexuality upshots in recompense along industry, level afterward reporting for the components frequently connected with sex disputes in recompense from managers and executives? Even, the belongings were unlike for adult male than for adult female and diverge along one's organizational point. Adult female who attained to the organizational stages of manager and executive and a thinner rate of diligences for equitable recompense than adult male behave at those stages.

[3] conducted research upon overall earnings compaction and low feminine provide relational to call for cut down a states sex wage breach. The investigators applied micro data for twenty-two countries across the 1985 to 1994 period of time, concluded that to a greater extent compacted male person remuneration constructions and lower female person final provision are both related to a lower sex remuneration breach.

Since it is expected that labour marketplace institutions are accountable as an authoritative assign by foreign deviations in remuneration inequality, the opposite relationship between the sex earnings gap and male person remuneration inequality evokes that wage-setting mechanisms, specified about whole sides of corporate bargaining systems that allow for comparatively eminent remuneration levels, enhance the relational yield of adult female, who inclined to amaze the lowest of the remuneration dispersion altogether states. Uniform on these aspect, it determine that the degree by collective-bargaining reporting in each state comprises importantly negatively concerned the sex disruption. Total, consequences provided potent certify that wage-setting establishments accept significant consequences on the sex yield gap and a few bear witness of the affect by the commercialize effects of issue and requirement likewise. 
[4] studied whether yearly semi permanent recompense for senior executive director is capable yearly and semipermanent recompense for higher-ranking Executive adult male. The grouping by Executive adult female enclosed those adult female depicted in the recompense boards of alternate affirmations for the firms in the Standard and Poor's for 1997.

Their recompense was compared to the recompense for two samples of executive adult male from S\&P 500 firms using DEA. The findings show that zero deviation in wage between adult male and adult female so, the recompense paying to executive adult female is equitable to the recompense paid to executive adult male.

[5] examined the sex breach in net income in peerless skill, applied science, engineering science and math's profession: chemical science. It driven the proportional effects of human being superior, labor commercialize construction, and employer favoritism on the sex yield breach of chemists. The information for this examine are incurred by the ACS 2000 census. According to the ACS census, male person chemists gained $30 \%$ to higher degree female chemists in 2000.

This net income breach is moldered by patterning net income as an exponential of sex, Department of Education, function experience, work function, case of employer, size of employer, area of work and a kind of family and demographic characteristics. The determinations depicts that eighty-three percentage of the sex breach is explained by deviations in creative features and seventeen percentage flows from to favoritism/a different measureless factors.

Go through and educational activity describe as very much of the sex breach - on normal, adult male get more eminent degrees of go through and informative action than do adult female. Body of work motive and employer likewise assist accounting for the remuneration breach - adult female are likelier to have posts in less paid chemistry posts.

[6] surveyed of business school graduates in 1988 and find out issue in the gender difference in the work is the pay. The determinations show that important percentage of the disruption in overall remuneration equals deserved to deviations in this component of full yield i.e. Depending on job execution. The sex divergence in contingent yield describes for fifty-eight $\%$ of sex divergence in ordinary full yield in the sampling; sexuality conflicts in basic remuneration describe for just forty-two percentage. When individual capital, individual features, and business and job steady are manipulated for, it comes out that approximately thirty-four percentage of the unadapted disruption in total remuneration that's not explained by sex disputes in endowments flows from to sex disputes in conditional yield. The concluding aspect of this explore is that women favor less pay jobs as at that place were job losing risk or minimum as compare to male.

[7] examined the remuneration and advancement dialogue applies of female person and male person civilize psychology practicians and university teachers of civilize psychology practicians called for to find out whether earnings conflicts exist between male person and female person employees in the field of civilize psychology, which makes convert a feminine-dominated career.

The sample distribution was overall of 191 female person and 115 male person academics and 148 female person and 56 male person civilize psychologists accomplished a study considering remuneration; dialogue applies, and line of work satisfaction. The determinations show that female person bring in to a lesser degree male person co-workers, assuring for yrs of experience and grade accomplishment. No sex conflicts were detected concerning staff participants' willingness to agree for raised remuneration; though, male person comprised to a greater extent expected to manage for advancement. As well, no sex conflicts were apparent in practicians' earnings and advancement dialogue endeavors, while no constituted potential, given the remuneration agenda constraints specific to jobs in the field of educational activity. 
[8] conducted research on the sex conflicts in basic pay and raises in the equivalent organization. The basic finding shows that women are paid to a lesser extent but given higher raises. There are list of reasons for pay gap in genders a few of them are organization structure, the long time off work (full time or part time) [9]. The first reason is the starting pay. The reason exposed for women high raises are because of the to a lesser extent information or don't have correct material present to construct a judgment. The other factor which is quite simple and correct as per organizations rule is that employees having low base pay acquire high raise as females are on the low base pay side.

[10] investigated the nature of compensation differentials between men and women and occupational independence in the formal sector in Jamaica. The data were collected for the year of 1988 as part of the Jamaica Tax Review Project under a contract with the America. Agency for International Development, by auditors skilled by the Revenue Board of the governance by Jamaica, who had the force of law to make a point complete disclosure of company payroll department and tax records. A total of 6,511 observations were gathered through an unequal and stratified sampling procedure. It discovered that degree to which wage differentials in Jamaica are explained by differences in case-by-case characteristics and the point to which they're left unexplained. An investigation of two more sources of differential handling is likewise presented.

First, the grade to which women are approximately likely to receive certain perks as part of their compensation is examined.

Second, the level to which men and women are segregated by occupation (possibly an important source of compensation difference) is researched. It is concluded that the differential treatment of women takes place through the differential rating of individual and occupational characteristics between men and women in the determination of absolute compensation, rather than through the discrepancy awarding of allowances or through the differential distribution of men and women across vocations. The findings show that differences in total compensation between men and women are less in jobs wherever women are better represented suggests that the greater occurrence of women comes through more difficult to treat them differently from men.

[11] endeavors to compensate that instability. The findings show that a favorable and important mutual consequence between sex and a long time of educational activity connected the remuneration net worth of workers. Whenever whole additional elements (for instance. Yrs of serving, line of work attitude) are kept stable, and then more advanced educational activity goes to an increment in the remunerations of both male person and female person. But then, in a higher place the Jr college degree, more educational activity brings out a greater gain in the remuneration rate for female person than for male person.

This field of study likewise determines that the raise for a adult female boosted to a direction view is importantly greater than that for a adult male who is equally upgraded. Sexuality and a long time of service of process create a exchangeable mutual consequence, while the affect upon remunerations are distant to a lesser extent visible. Hence, it is concluded that the virtually booming direction for female person workers to constrict the remuneration breach between themselves and male person workers are to follow a more eminent degree of educational activity.

On the social charge, bringing out politics participation to control working class marketplace favoritism, producing a more like dealing of family obligation by both adult male and adult female, and demoralizing crosswise and perpendicular occupational separatism by gender are too necessary in reducing sex remuneration differentials.

[12] looked into sex remuneration inequality, specifically, whether net income is impacted by the sex authorship of validations' managerial and supervisory faculty. This practical analysis are supported two interconnected information adjusts. 
The fact on humans and their lines of work was compiled in the 1991 Swedish degree of populating view. That sample distribution comprises by around 6,000 persons spokesperson of the Swedish universe of age eighteen to seventy-five. This action yielded a sample distribution of 2,135 establishments, which compensate the 1991 Swedish formation view. The findings depict that gender-differentiated right of entry to organizational authority structure is requirement in explaining adult female comparatively low remunerations. Adult female who do piece of work in establishment in which comparatively a lot of the managers are adult male bear lower remunerations than adult female with related qualifications and line of work demands in formation with more adult female in the hierarchy.

[13] studied the leading consequences of sex with the relationship between modifying employers and recompense accomplishment. This analyze used data from 739 United States of America managers and professional person and 593 Hong Kong Taiwanese managers and professional person that were assembled through members of a joint association that in 1991, was constituted to supply relative info just about turnover rate and recompense orders to participants. Information were firstly gathered in 1991 from 1591 responders by forty portion five hundred corporations incoming America and by 1447 responders by fifty-five big in public merchandise fellowships in Hong Kong.

Even though at that place were no gender-based recompense conflicts ahead of time in the vocations of these persons, broad yield conflicts favoring adult male were noticed in 1999 just amongst those who had observed an foreign labour marketplace strategy. The findings show that this observable fact is not apart to labour market by the America and fortify the aspect that a great deal of the discovered remuneration derivative preferring adult male has its inceptions in additional-business firm mobility, not intra-firm sex favoritism.

[14] investigated regular female workers have low pay scale jobs, low prestige jobs as compare to males with having same qualifications and experience. It is expressed that women are dissatisfied with men against their salaries and with their jobs. According to a research female employees have low starting expectation in their vocation as compare to men. The factors that differentiate male and female employees vocation expectations came out these basis: career path, education, occupational choices, performance, difficulty at workplace and so on. The other most authoritative thing on gender differences is job stimulants.

That is women less expectations of salary as compare to male as they are less qualified or to a lesser extent competent at work. The other main factor is the perception of the lines of work between the male and female employees. According to one of the research women are less motivated they become quickly demotivated as compare to men and they devalue their own work. One of the most interesting factors constitutes that women are more satisfied with salaries as compare to men on the basis of they don't conceive money everything as compare to men.

$[15,16]$ analyzed the recompense for forty-seven feminine chief executive officer who accommodated place during 2000 and equate their remuneration to a equated sampling distribution of business firm channelized along male person chief executive officer. It covered whole portions of their remuneration, admitting immediate payment earnings, bonus, semi permanent bonuses addition the appraise of alternatives allotted for financial year 2000. It included across forty feminine chief executive officers as in public merchandised companies and equated couples of comparable to male person chief executive officer. The findings reveal that at that place represents a statistical conflict between male person and female person expected recompense.

[17] estimated salary equalities as from each one by 7 occupational classes and the combine sampling distribution. It supported the information from the 1991. When perks are omitted from the recompense measurement, a sex coefficient constitutes statistically important with of seven occupational classes, the omission representing the almost female- 
dominated class. The findings show that admitting perks earns a significant conflict in the analysis of gaining derivatives. For that whatever appraises of remuneration that excluded perks could bring about misdirecting effects equally to the creation, level, consequences, and origin of marketplace favoritism.

\begin{tabular}{|c|c|c|c|c|}
\hline \multicolumn{5}{|c|}{ Unrestricted Cointegration Rank Test (Trace) } \\
\hline $\begin{array}{l}\text { Hypothesized } \\
\text { No. of CE(s) }\end{array}$ & Eigenvalue & $\begin{array}{l}\text { Trace } \\
\text { Statistic }\end{array}$ & $\begin{array}{l}0.05 \\
\text { Critical Value }\end{array}$ & Prob." \\
\hline None * & 0.072897 & 135.2689 & 15.49471 & 0.0000 \\
\hline At most $1^{*}$ & 0.035815 & 43.98575 & 3.841465 & 0.0000 \\
\hline \multicolumn{5}{|c|}{$\begin{array}{l}\text { Trace test indicates } 2 \text { cointegrating eqn(s) at the } 0.05 \text { level } \\
\text { " denotes rejection of the hypothesis at the } 0.05 \text { level } \\
\text { "MacKinnon-Haug-Michelis (1999) p-values }\end{array}$} \\
\hline \multicolumn{5}{|c|}{ Unrestricted Cointegration Rank Test (Maximum Eigenvalue) } \\
\hline $\begin{array}{l}\text { Hypothesized } \\
\text { No. of CE(s) }\end{array}$ & Eigenvalue & $\begin{array}{l}\text { Max-Eigen } \\
\text { Statistic }\end{array}$ & $\begin{array}{l}0.05 \\
\text { Critical Value }\end{array}$ & Prob." \\
\hline None * & 0.072897 & 91.28315 & 14.26460 & 0.0000 \\
\hline At most $1^{*}$ & 0.035815 & 43.98575 & 3.841465 & 0.0000 \\
\hline \multirow{2}{*}{\multicolumn{5}{|c|}{$\begin{array}{l}\text { Max-eigenvalue test indicates } 2 \text { cointegrating eqn(s) at the } 0.05 \text { level } \\
\text { " denotes rejection of the hypothesis at the } 0.05 \text { level } \\
\text { "MacKinnon-Haug-Michelis (1999) p-values }\end{array}$}} \\
\hline & & & & \\
\hline \multicolumn{5}{|c|}{ COMPENSAT MALE_TO_FEMALE_RATIO_IN_AGRI_SECTOR } \\
\hline$-1.90 \mathrm{E}-07$ & $2 . \overline{5586 \overline{14}}$ & & & \\
\hline $3.57 \mathrm{E}-08$ & 0.775145 & & & \\
\hline \multicolumn{5}{|c|}{ Unrestricted Adjustment Coefficients (alpha): } \\
\hline DICOMPENS & 820102.4 & -1705851. & & \\
\hline D(MALE TO & -0.087753 & -0.129907 & & \\
\hline \multicolumn{2}{|c|}{1 Cointegrating Equation(s): } & Log likelihood & \multicolumn{2}{|l|}{-21982.86} \\
\hline \multicolumn{5}{|c|}{ Normalized cointegrating coefficients (standard error in parentheses) } \\
\hline \multicolumn{5}{|c|}{ COMPENSAT MALE_TO_FEMALE_RATIO_IN_AGRI_SECTOR } \\
\hline $\begin{array}{rr}1.000000 \quad & -12 \overline{4407 \overline{7} 7} \\
& (651845 .)\end{array}$ & \multicolumn{4}{|c|}{$\begin{array}{l}\text { ALE_TO_FEMALE_RATIO_IN_AGRI_SECTOR } \\
-12440777\end{array}$} \\
\hline \multicolumn{5}{|c|}{ Adjustment coefficients (standard error in parentheses) } \\
\hline D(COMPENS & -0.155481 & $(0.05195)$ & & \\
\hline D(MALE TO & \multicolumn{2}{|l|}{$\begin{array}{l}1.66 \mathrm{E}-08 \\
(4.1 \mathrm{E}-09)\end{array}$} & & \\
\hline
\end{tabular}

Fig. 1. Co-movements between Male to Female employment ratio and Salary compensations in agricultural sector. 


\section{Research Method}

To analyze the possible co-movement between the Male to Female employment ratio and Salary compensations in agricultural sector of Pakistan, the time series data for the yearly period of 1990 to 2020 for agriculture sector are taken from the publically available source i.e. website of World Bank.

\section{Results}

The investigation on the co-movements between Male to Female employment ratio and Salary compensations in agricultural sector, we found that there is a significant cointegration between the outlined variables.

The above table presents detailed results of co-movements between Male to Female employment ratio and Salary compensations in agricultural sector, including the trace test and the max-eigenvalue test at the 5\% significance level. From Table, both the trace and max-eigenvalue tests support two cointegrating vector at the $5 \%$ significance level as the sig value is less than 0.05 .

\section{Discussion and Conclusion}

This study has been conducted in order to identify whether there is the co-movements between Male to Female employment ratio and Salary compensations in agricultural sector of Pakistan. The result indicated that there is a long term relationship exists in between Male to Female employment ratio and Salary compensations in agricultural sector of Pakistan

The econometrical findings support to set economic policies and rules for institutions development. As result confirmed that there are strong and significant commoving patterns of Male to Female employment ratio and Salary compensations in agricultural sector in the country, this finding is consistent with most of the empirical findings in the literature although few authors believed that Gender difference was nothing with Compensation (wages) in the agriculture sector.

\section{References}

1. S.M. Adams et al., Gender in Management: An International Journal 25(5), 366-385 (2010)

2. M.V. Vinichenko et al., Espacios 40(19) (2019)

3. F.D. Blau, L.M. Kahn, Journal of Labor Economics 21(1), 106-144 (2003)

4. W. Bowlen et al., The Journal of Operational Research Society 54(7), 751-757 (2003)

5. P. Broyles, International Journal of Sociology and Social Policy 29(5/6), 214-226 (2009)

6. K.W. Chauvin, R.A. Ash, Industrial and Labor Relations Review 47(4), 634-649 (1994)

7. L. M. Crothers et al., Gender in Management: An International Journal 25(7), 605-626 (2010)

8. M. M. Harris et al., Journal of Business and Psychology 16(4), 499-514 (2002)

9. D. Ushakov, E. Kozlova, Actual Problems of Economics 163(1), 391-397 (2015)

10. J. Hotchkiss, R. Moore, Development and Cultural Change 44(3), 657-676 (1996) 
11. T. Huang, International Journal of Manpower 20(6), 361-374 (1999)

12. M. Hultin, R. Szulkin, Administrative Science Quarterly 44(3), 453-472 (1999)

13. S. Lam, G. Dreher, Journal of Organizational Behavior 25(7), 791-805 (2004)

14. B. Major, E. Konar, Academy of Management Journal 27(4), 777-792 (1984)

15. D. Ushakov, Actual Problems of Economics 169(7), 315-324 (2015)

16. N. Mohan, J. Ruggiero, The Journal of Operational Research Society 54(12), 12421248 (2003)

17. E. Solberg, T. Laughlin, Industrial and Labor Relations 48(4), $692-708$ (1995) 